\title{
Evaluation of Daptomycin Non-Susceptible Staphylococcus aureus for Stability, Population Profiles, mprF Mutations, and Daptomycin Activity
}

\author{
Molly E. Steed · Ashley D. Hall • Hossein Salimnia • \\ Glenn W. Kaatz $\cdot$ Keith S. Kaye $\cdot$ Michael J. Rybak
}

To view enhanced content go to www.infectiousdiseases-open.com

Received: August 22, 2013 / Published online: November 29, 2013

(C) The Author(s) 2013. This article is published with open access at Springerlink.com

\begin{abstract}
Introduction: Despite studies examining daptomycin non-susceptible (DNS)

Electronic supplementary material The online version of this article (doi:10.1007/s40121-013-0021-7) contains supplementary material, which is available to authorized users.
\end{abstract}

M. E. Steed · A. D. Hall · M. J. Rybak ( $₫)$ Anti-Infective Research Laboratory, Eugene Applebaum College of Pharmacy and Health Sciences, Wayne State University, 259 Mack Avenue, Detroit, MI 48201, USA

e-mail:m.rybak@wayne.edu; mrybak@dmc.org

H. Salimnia

Microbiology Division, Detroit Medical Center University Laboratories, Detroit, USA

H. Salimnia - G. W. Kaatz - K. S. Kaye · M. J. Rybak School of Medicine, Wayne State University, Detroit, USA

G. W. Kaatz

John D. Dingell Veteran Affairs Medical Center, Detroit, USA

K. S. Kaye · M. J. Rybak

Detroit Medical Center, Detroit, USA

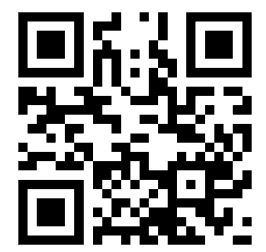

Enhanced content for this article is available on the journal web site: www.infectiousdiseases-open.com
Staphylococcus aureus, examination of the stability and population profiles is limited. The objective was to evaluate the stability, population profiles, and daptomycin activity against DNS isolates.

Methods: The stability of 12 consecutive clinical DNS strains was evaluated by minimum inhibitory concentration (MICs) and population analysis profiles before and after 5 days of serial passage. Two pairs of DNS $S$. aureus having the same daptomycin MIC but different daptomycin population profiles were evaluated via an in vitro pharmacokinetic/ pharmacodynamic (PK/PD) model of simulated endocardial vegetations for $96 \mathrm{~h}$ against daptomycin 6 and $10 \mathrm{mg} / \mathrm{kg} /$ day. The sequence of $m p r F$ was determined for these isolates before and after $96 \mathrm{~h}$ of daptomycin exposure in the in vitro PK/PD model.

Results: Daptomycin MIC values were $2-4 \mathrm{mg} / \mathrm{L}$ (via Microscan) for the 12 clinical isolates; 9 were confirmed DNS and 3 were within 1 tube dilution of Microscan (daptomycin MIC $1 \mathrm{mg} / \mathrm{L}$ ). All were stable to serial passage. There was variation in the isolates susceptibility to daptomycin on population analysis (daptomycin population AUC 14.01-26.85). The killing patterns of 
daptomycin 6 and $10 \mathrm{mg} / \mathrm{kg} /$ day differed between isolates with a left-shift and rightshift population profile to daptomycin. Two strains developed additional $m p r F$ mutations during daptomycin exposure in the in vitro PK/ PD model resulting in P314L, L826F, S337L and a novel Q326Stop mutation.

Conclusions: The collection of DNS isolates was stable and displayed variation in susceptibility to daptomycin on population profile. Further research examining this clinical relevance is warranted.

Keywords: Daptomycin; Daptomycin nonsusceptible; Infectious diseases; mprF; Staphylococcus aureus

\section{INTRODUCTION}

Daptomycin is a cyclic lipopeptide antibiotic with activity against Gram-positive organisms that received approval from the United States Food and Drug Administration in September, 2003 [1]. It is a concentration-dependent bactericidal antibiotic that acts by binding to and inserting into the bacterial cytoplasmic membrane resulting in rapid depolarization and deregulation of several cell functions such as DNA, RNA and protein synthesis [2-4]. Daptomycin susceptibility in Staphylococcus aureus is defined as a minimum inhibitory concentration (MIC) of $\leq 1 \mathrm{mg} / \mathrm{L}$ and any strain with an MIC $>1 \mathrm{mg} / \mathrm{L}$ is considered daptomycin non-susceptible (DNS) [5].

The development of DNS in $S$. aureus laboratory studies, clinical trials, and postmarketing surveillance has been relatively low. Spontaneous mutagenesis in S. aureus for DNS appears at a rate of less than $10^{10}$ [6]. Staphylococcus aureus with DNS can be obtained via extended serial passage with increasing daptomycin concentrations and via chemical mutagenesis. An in vitro model evaluated standard vancomycin and daptomycin dosing regimens against 5 clinical strains of $S$. aureus that developed DNS in vivo [7]. The DNS could only be replicated in vitro in $1 / 5$ of these strains and with vancomycin but not daptomycin exposure. Interestingly, the DNS in this $S$. aureus strain was unstable and reverted back to susceptible upon passage on antibiotic free media. Only 7 of 120 patients in the phase III trial for $S$. aureus bacteremia and infective endocarditis trial developed isolates with DNS [8]. Evaluation of 22,858 S. aureus isolated in North America from 2005 to 2010 revealed only 14 strains with a daptomycin MIC of $\geq 2 \mathrm{mg} / \mathrm{L}$, and no trend indicating increasing MICs was noted [9].

Daptomycin non-susceptibility in $S$. aureus does not appear to be an all or nothing phenomenon, but instead a series of incremental changes that increase the MIC [10-15]. To date, four main genetic changes (mprF, yycG, rpoB/rpoC, dltABCD) have been associated with increased MIC and DNS in $S$. aureus. Mutations in or overexpression of the $m p r F$ gene is commonly found in both laboratory derived and clinical DNS isolates [11-14]. Increased quantities of the MprF protein, a lysylphosphatidylglycerol synthase, is thought to contribute to DNS by affecting the composition of the cell membrane via translocation of positively charged phospholipids to the outer side of the cytoplasmic membrane and by lysinylation of membrane phosphatidylglycerol (PG) to generate lysyl-PG (LPG) thereby increasing positive surface charge [14-16]. Recently mutations in the phospholipid biosynthesis genes cardiolipin synthase (cls2) and CDP-diacylglycerol-glycerol-3-phosphate 3 
phosphatidyltransferase ( $p g s A$ ) have been found in clinical DNS strains [17]. Another altered protein sometimes found in DNS strains is YycG, which is one of two components of a response regulator system involved in the metabolism of the cytoplasmic membrane and cell wall [11]. The proteins RpoB and RpoC, which comprise the $\beta$ and $\beta^{\prime}$ subunit of RNA polymerase, have also been found with amino acid substitutions in DNS $S$. aureus strains [11]. Recently, a single nucleotide polymorphism in $r p o B$ from a laboratory derived DNS $S$. aureus was associated with decreased negative surface charge, increased cell wall thickness, and both vancomycin and daptomycin heteroresistance [18]. Additionally, increased expression of the dltABCD operon increases D-alanylation of cell wall teichoic acids contributing to an increase in positive surface charge [13]. Recent work has also suggested membrane proteins may augment the bactericidal effects of daptomycin, and alteration or loss of these proteins may contribute to DNS [15]. It has also been proposed that changes in carotenoid biosynthesis in $S$. aureus can increase membrane rigidity and contribute to increases in daptomycin MIC values [19]. Overall, DNS $S$. aureus strains show altered membrane potential, changes in membrane fluidity, increased positive membrane surface charge, and decreased membrane depolarization [10-15]. It is hypothesized that the increase in cytoplasmic membrane surface charge repels the active daptomycin- $\mathrm{Ca}^{2+}$ complex and therefore impedes interaction of daptomycin with the membrane $[10,20]$. There are likely other genetic changes that contribute to DNS in $S$. aureus as strains exhibiting elevated MICs often have only some of the changes mentioned above [21-24]. There is still much room for discovery of novel cell membrane and genetic changes in DNS strains of $S$. aureus.
We have observed that some of the $S$. aureus strains identified as DNS by the clinical microbiology laboratory at our institution using Microscan ${ }^{\circledR}$ (Dade Behring, Deerfield, IL, USA) were actually susceptible via broth microdilution following passage on antibiotic free agar or time being stored at $-80{ }^{\circ} \mathrm{C}$. This observation led us to question the stability of these isolates. Additionally, previous in vitro work we have done with DNS strains has demonstrated variable activity of daptomycin $[25,26]$. In some cases, daptomycin regimens of $10 \mathrm{mg} / \mathrm{kg}$ per day maintain antibacterial activity and led us to hypothesize that some $S$. aureus strains with DNS may still be treatable with daptomycin. The objectives of this study were to evaluate the stability of DNS strains from the clinical microbiology laboratory and to evaluate the activity of daptomycin regimens against DNS $S$. aureus strains with differing daptomycin population profiles.

\section{MATERIALS AND METHODS}

\section{Bacterial Strains}

Twelve consecutive clinical $S$. aureus strains, each having a daptomycin MIC of $\geq 2 \mathrm{mg} / \mathrm{L}$, were collected from the clinical microbiology laboratory beginning in May 2009 and were evaluated for stability of DNS. All isolates were transported from the clinical microbiology laboratory to our laboratory on the original blood agar isolation plate within hours of obtaining the clinical microbiology laboratory susceptibility results to prevent any passes.

\section{Antimicrobials}

Daptomycin analytical grade powder was obtained from Cubist Pharmaceuticals, Lexington, MA, USA. 


\section{Media}

Mueller-Hinton broth II (MHBII, Difco, Detroit, MI, USA) supplemented to $50 \mathrm{mg} / \mathrm{L}$ calcium was used for daptomycin susceptibility testing according to Clinical and Laboratory Standards Institute (CLSI) guidelines and MHBII supplemented to $75 \mathrm{mg} / \mathrm{L}$ was used for in vitro model experiments to account for calcium binding to albumin. Colony counts were determined using Tryptic Soy Agar (TSA; Difco, Detroit, MI, USA) plates. Mueller-Hinton agar prepared from MHBII supplemented with $50 \mathrm{mg} / \mathrm{L}$ of calcium and $15 \mathrm{~g} / \mathrm{L}$ of Bacto ${ }^{\mathrm{TM}}$ Agar (Beckton, Dickson \& Company, Sparks, MD, USA) was used for population analysis profiles (PAP).

\section{Serial Passage}

All isolates confirmed as DNS by our laboratory were passed on TSA five consecutive times. Isolates with a daptomycin MIC remaining $\geq 2 \mathrm{mg} / \mathrm{L}$ ( \pm 1 tube dilution standard error) after 5 serial passages were defined as stable DNS $S$. aureus strains and isolates reverting back to a daptomycin MIC of $<1 \mathrm{mg} / \mathrm{L}$ were defined as unstable DNS $S$. aureus strains.

\section{Susceptibility Testing}

The MICs of daptomycin obtained by Microscan and for the isolates obtained with each serial passage were confirmed by broth microdilution (BMD) using an inoculum of $10^{6} \mathrm{CFU} /$ milliliter $(\mathrm{mL})$ in duplicate according to CLSI standard methods and by Etest according to the manufacturer's guidelines [5]. S. aureus ATCC 25923 was used as a control strain. After greater than 2 years of storage at $-80^{\circ} \mathrm{C}$ the daptomycin MIC of all isolates was retested to assess the effect of storage on the stability of the MIC.

\section{Molecular Biology}

All strains were characterized for SCCmec type, Panton-Valentine Leukocidin (PVL) status, and agr function and group by previously described methods [27-31]. S. aureus isolates were evaluated by pulse field gel electrophoresis (PFGE) using SmaI-digested DNA, as described previously [32]. Gels were run at $6 \mathrm{~V} / \mathrm{cm}, 14^{\circ} \mathrm{C}$, at an included angle of $120^{\circ}$, on a $1.2 \%$ agarose gel with pulse times of 5-35 s for $21 \mathrm{~h}$. Strain relatedness was determined by visual inspection of the gel using the criteria of Tenover et al. and DICE coefficient using BioNumerics Software (Version 4.6, Applied Maths, Saint-MartensLatem, Belgium) [33].

\section{Daptomycin Population Susceptibility Profiles}

Fifty microliters of a $\sim 10^{8} \mathrm{CFU} / \mathrm{mL}$ suspension of each strain was plated onto MHA plates with calcium containing daptomycin (concentrations ranging from 0.5 to $6 \mathrm{mg} / \mathrm{L}$ ) using an automatic spiral plating device (WASP; DW Scientific, West Yorkshire, UK). After $48 \mathrm{~h}$ of incubation at $37^{\circ} \mathrm{C}$, colony counts were determined using an automated colony counter (Synoptics Limited, Frederick, MD, USA). The lower limit of detection for colony count was $2 \log _{10} \mathrm{CFU} / \mathrm{mL}$. Curves were constructed by plotting colony counts $\left(\log _{10}\right.$ $\mathrm{CFU} / \mathrm{mL}$ ) versus concentration. Strain SA-684, previously determined to be stable to passage, was used as a control strain [15].

\section{In Vitro Model Experiment}

Two pairs of DNS S. aureus strains with the same MIC values by Microscan and BMD but displaying different PAPs (left shift vs. right shift) were evaluated in an in vitro 
pharmacokinetic/pharmacodynamic (PK/PD) model of simulated endocardial vegetations.

\section{Simulated Endocardial Vegetations}

Organism stocks were prepared by creating lawns on TSA plates and incubating at $37^{\circ} \mathrm{C}$ overnight. Organisms were swabbed from the growth plates into five mL test tubes of MHBII, diluted 1:10 and resulting in a concentration of approximately $10^{10} \mathrm{CFU} / \mathrm{mL}$. Simulated Endocardial Vegetations (SEVs) were prepared in $1.5 \mathrm{~mL}$ siliconized eppendorf tubes by mixing $0.05 \mathrm{~mL}$ of organism suspension (final inoculum $10^{9} \mathrm{CFU} / 0.5 \mathrm{~g}$ ), $0.5 \mathrm{~mL}$ of human cryoprecipitate from volunteer donors (American Red Cross, Detroit, MI, USA), $0.025 \mathrm{~mL}$ of platelets. Bovine thrombin $(5,000$ units $/ \mathrm{mL}$ ) $0.05 \mathrm{~mL}$, was added to each tube after insertion of a sterile monofilament line into the mixture. The resultant SEVs were then removed from the eppendorf tubes with a sterile 21-gauge needle and introduced into the model. This methodology results in SEVs consisting of approximately $3-3.5 \mathrm{~g} / \mathrm{dL}$ of albumin and $6.8-7.4 \mathrm{~g} / \mathrm{dL}$ of total protein.

\section{In Vitro PK/PD Model}

An in vitro model, consisting of a $250 \mathrm{~mL}$ two compartment glass apparatus with ports where the SEVs were suspended, was utilized for all simulations. The apparatus was prefilled with media and antibiotics were administered as boluses over a $96 \mathrm{~h}$ time period into the central compartment via an injection port. Antibiotic regimens evaluated included daptomycin $6 \mathrm{mg} / \mathrm{kg}$ every $24 \mathrm{~h}$ (peak, $98.6 \mathrm{mg} / \mathrm{L}$; average half-life, $8 \mathrm{~h}$ ) and daptomycin $10 \mathrm{mg} / \mathrm{kg}$ every $24 \mathrm{~h}$ (peak $141.1 \mathrm{mg} / \mathrm{L}$; average half-life $8 \mathrm{~h}$ ) [34]. The model apparatus was placed in a $37^{\circ} \mathrm{C}$ water bath throughout the procedure and a magnetic stir bar was placed in the media for thorough mixing of the drug in the model. Fresh media was continuously supplied and removed from the compartment along with the drug via a peristaltic pump (Masterflex, Cole-Parmer Instrument Company, Chicago, IL, USA) set to simulate the half-lives of the antibiotics. All models were performed in duplicate to ensure reproducibility.

\section{Pharmacodynamic Analysis}

Two SEVs were removed from each model (total of 4$)$ at $0,4,8,24,32,48,56,72$ and $96 \mathrm{~h}$. The SEVs were homogenized and diluted in cold saline and then plated onto TSA plates. Plates were incubated at $37^{\circ} \mathrm{C}$ for $24 \mathrm{~h}$ at which time colony count was performed. The total reduction in $\log _{10} \mathrm{CFU} / \mathrm{g}$ over $96 \mathrm{~h}$ was determined by plotting time kill curves. Bactericidal activity (99.9\% kill) was defined as $\mathrm{a} \geq 3 \log _{10} \mathrm{CFU} / \mathrm{g}$ reduction in colony count from the initial inoculum, bacteriostatic activity was defined as a $<3 \log _{10} \mathrm{CFU} / \mathrm{g}$ reduction in colony count from the initial inoculum, and inactive was defined as no observed reductions in initial inocula. The time to achieve a $99.9 \%$ reduction was determined by linear regression or visual inspection (if $r^{2} \geq 0.95$ ). Susceptibility was performed on the $96 \mathrm{~h}$ sample by broth microdilution.

\section{Pharmacokinetic Analysis}

Pharmacokinetic samples were obtained in duplicate through the injection port of each model at $0.5,1,2,4,8,24,32,48,56,72$ and $96 \mathrm{~h}$ for verification of target antibiotic concentrations. All samples were stored at $-70{ }^{\circ} \mathrm{C}$ until ready for analysis. Concentrations of daptomycin were determined by 
microbioassay utilizing Micrococcus luteus ATCC 9341. Briefly, blank $1 / 4^{\prime \prime}$ disks were placed on a pre-swabbed plate of appropriate antibiotic medium and spotted with $10 \mu \mathrm{L}$ of the standards or samples. Each standard was tested in duplicate. Plates were incubated for $18-24 \mathrm{~h}$ at $37^{\circ} \mathrm{C}$ at which time the zone sizes were measured. The half-lives, area under the curve (AUC), AUC/MIC and peak concentrations of the antibiotics were determined by the trapezoidal method utilizing PK Analyst software (Version 1.10, MicroMath Scientific Software, Salt Lake City, UT, USA).

\section{Resistance}

Development of resistance in the SEV model was evaluated at multiple time points throughout the simulation at $24,48,72$, and 96 h. $100 \mu \mathrm{L}$ samples from each time point were plated on MHA plates containing three times the drug's MIC to assess the development of resistance. Plates were then examined for growth after $24-48 \mathrm{~h}$ of incubation at $37^{\circ} \mathrm{C}$. MICs were determined for all mutants identified via this method (by microdilution and Etest as described above).

\section{Statistical Analysis}

Changes in CFU/g at 24, 48, 72, and $96 \mathrm{~h}$ were compared by two-way analysis of variance with Tukey's post hoc test. A $P$ value of $\leq 0.05$ was considered significant. Paired continuous data was evaluated with a paired $t$ test. All statistical analyses were performed using SPSS Statistical Software (Release 19.0, SPSS, Inc., Chicago, IL, USA).

\section{mprF Sequencing}

All 4 isolates placed in the SEV in vitro model and the isolates recovered at $96 \mathrm{~h}$ were evaluated for mutations in the $m p r F$ gene. The mprF genes were amplified by PCR using previously described primers [12]. The products were sequenced in both directions by an automated dideoxy chain termination method by the Applied Genomics Technology Center, Wayne State University. Nucleotide sequence analysis was performed with DS Gene 1.5 (Accelrys, Inc. San Diego, CA, USA).

\section{Membrane Potential Measurements}

Membrane potential was compared between the stable DNS $S$. aureus strains and the daptomycin susceptible parent (when available and confirmed isogenic by PFGE). Strains were grown to early exponential phase in $20 \mathrm{~mL}$ of SMHB, pelleted, washed twice with HEPES buffer ( $\mathrm{pH}$ 7.2, containing $50 \mathrm{mg} / \mathrm{L}$ $\mathrm{Ca}^{2+}$ ) and then re-suspended in HEPES $\left(\mathrm{OD}_{600}=0.2\right)$. Aliquots were transferred to a cuvette containing a stir bar, then $\mathrm{KCl}$ $(100 \mathrm{mM})$ was added and the cuvette was placed in the heated chamber of a FluoroMax-3 spectrofluorometer $\left(\lambda_{\mathrm{ex}}=622 \mathrm{~nm}\right.$ and $\lambda_{\mathrm{em}} 670 \mathrm{~nm}$ at $37^{\circ} \mathrm{C}$ ) (Horiba Jobin-Yvon Inc., Edison, NJ, USA). Cells were incubated with the membrane potential-sensitive dye $\mathrm{DiSC}_{3}(0.1 \mathrm{mg} / \mathrm{mL})$ for $10 \mathrm{~min}$. Conditions included no antibiotic, nisin $(25 \mathrm{mg} / \mathrm{L})$ and daptomycin $(8 \mathrm{mg} / \mathrm{L})$. The membranedepolarizing activity of daptomycin over $60 \mathrm{~min}$ was calculated as follows: \% depolarization $=\left[\left(F_{\mathrm{d}}-F_{\mathrm{c}}\right) /\left(F_{\mathrm{n}}-F_{\mathrm{c}}\right)\right] \times 100$, where $F_{\mathrm{d}}, F_{\mathrm{c}}$ and $F_{\mathrm{n}}$ are fluorescence measurements with daptomycin, no antibiotic and nisin, respectively. Results are expressed as the mean of two independent experiments.

This article does not contain any studies with human or animal subjects performed by any of the authors. 
Table 1 Minimum inhibitory concentration values, daptomycin population analysis area under curve (AUC) values and molecular characteristics

\begin{tabular}{|c|c|c|c|c|c|c|c|c|c|}
\hline \multirow[t]{3}{*}{ Isolate } & \multicolumn{3}{|c|}{ MIC value $(\mathrm{mg} / \mathrm{L})$} & \multirow[t]{3}{*}{ DAP AUC } & \multirow[t]{3}{*}{ SCCmec } & \multirow[t]{3}{*}{ USA } & \multirow[t]{3}{*}{ PVL } & \multirow{2}{*}{\multicolumn{2}{|c|}{ AGR }} \\
\hline & \multicolumn{2}{|l|}{ Initial } & \multirow{2}{*}{$\begin{array}{l}\text { Storage } \\
\text { BMD }\end{array}$} & & & & & & \\
\hline & Microscan & $\overline{\text { BMD }}$ & & & & & & Type & $\overline{\text { Function }}$ \\
\hline $\mathrm{R} 6297$ & 2 & 1 & 1 & 14.01 & 2 & - & - & 2 & - \\
\hline $\mathrm{R} 6515$ & 2 & 1 & 1 & 16.87 & 2 & - & - & 2 & - \\
\hline $\mathrm{R} 6738$ & 2 & 1 & 1 & 18.08 & 4 & 300 & + & 1 & - \\
\hline $\mathrm{R} 6212$ & 2 & 2 & 2 & 18.45 & 2 & - & - & 2 & + \\
\hline R6737 & 2 & 2 & 2 & 20.03 & 2 & - & - & 2 & - \\
\hline $\mathrm{R} 6516^{\mathrm{a}}$ & 2 & 2 & 2 & 22.09 & 4 & - & - & 1 & - \\
\hline $\mathrm{R} 6003$ & 4 & 2 & 4 & 22.14 & 2 & - & - & 2 & - \\
\hline $\mathrm{R} 6253$ & 4 & 2 & 2 & 23.66 & 4 & 300 & + & 1 & + \\
\hline $\mathrm{R} 6747$ & 4 & 2 & 2 & 22.28 & 2 & - & - & 2 & - \\
\hline R6219 & 4 & 4 & 2 & 20.68 & 4 & 300 & - & 1 & + \\
\hline$R 6255$ & 4 & 4 & 4 & 26.85 & 2 & - & + & 2 & - \\
\hline R6827 & 4 & 4 & 0.5 & 21.24 & 4 & 300 & + & 1 & + \\
\hline
\end{tabular}

$B M D$ broth microdilution, DAP daptomycin, SCCmec Staphylococcal cassette chromosome mec, USA Staphylococcal USA clone type, PVL Panton-valentine leukocidin (+present, -absent), AGR accessory gene regulator (function: +functional, - dysfunctional)

${ }^{\text {a }}$ USA clone type could not be interpreted from PCR

\section{RESULTS}

MICs as determined by both Microscan and BMD for the twelve DNS $S$. aureus isolates are displayed in Table 1. As can be seen, all isolates had the Microscan MICs confirmed by BMD (within 1 tube dilution standard error). The spread for MIC values was as follows: three isolates with $2 \mathrm{mg} / \mathrm{L}$ (Microscan) and $1 \mathrm{mg} / \mathrm{L}$ (BMD), three isolates with $2 \mathrm{mg} / \mathrm{L}$ (Microscan/ $\mathrm{BMD})$, three isolates with $4 \mathrm{mg} / \mathrm{L}$ (Microscan) and $2 \mathrm{mg} / \mathrm{L}$ (BMD), and three isolates with $4 \mathrm{mg} / \mathrm{L}$ (Microscan/BMD). All isolates were stable over five serial passages on drug free TSA. Etest MICs confirmed the daptomycin MIC value within 1 tube dilution. Examination of the twelve isolates by daptomycin population analysis revealed both left-shift and right-shift profiles within the 4 MIC value groups (Fig. 1ad). Additionally, the daptomycin AUC values (Table 1) increase as the MIC values increase (Table 1). Retesting of the isolate's daptomycin MIC values by BMD after greater than 2 years of storage at $-80^{\circ} \mathrm{C}$ revealed that the MIC values were stable ( \pm 1 tube dilution standard error) for 11/12 isolates (Table 1). One isolate, R6827, displayed a daptomycin MIC decrease from 4 to $0.5 \mathrm{mg} / \mathrm{L}$ on retesting after storage.

Molecular characterization of the twelve strains is displayed in Table 1 . The activity of daptomycin against 2 selected pairs (4 isolates total) in the in vitro PK/PD model of SEVs with the same MIC values but differing daptomycin PAPs is shown in Fig. 2a-d. A daptomycin dose response relationship was observed for all four strains. The daptomycin $6 \mathrm{mg} / \mathrm{kg}$ regimen 

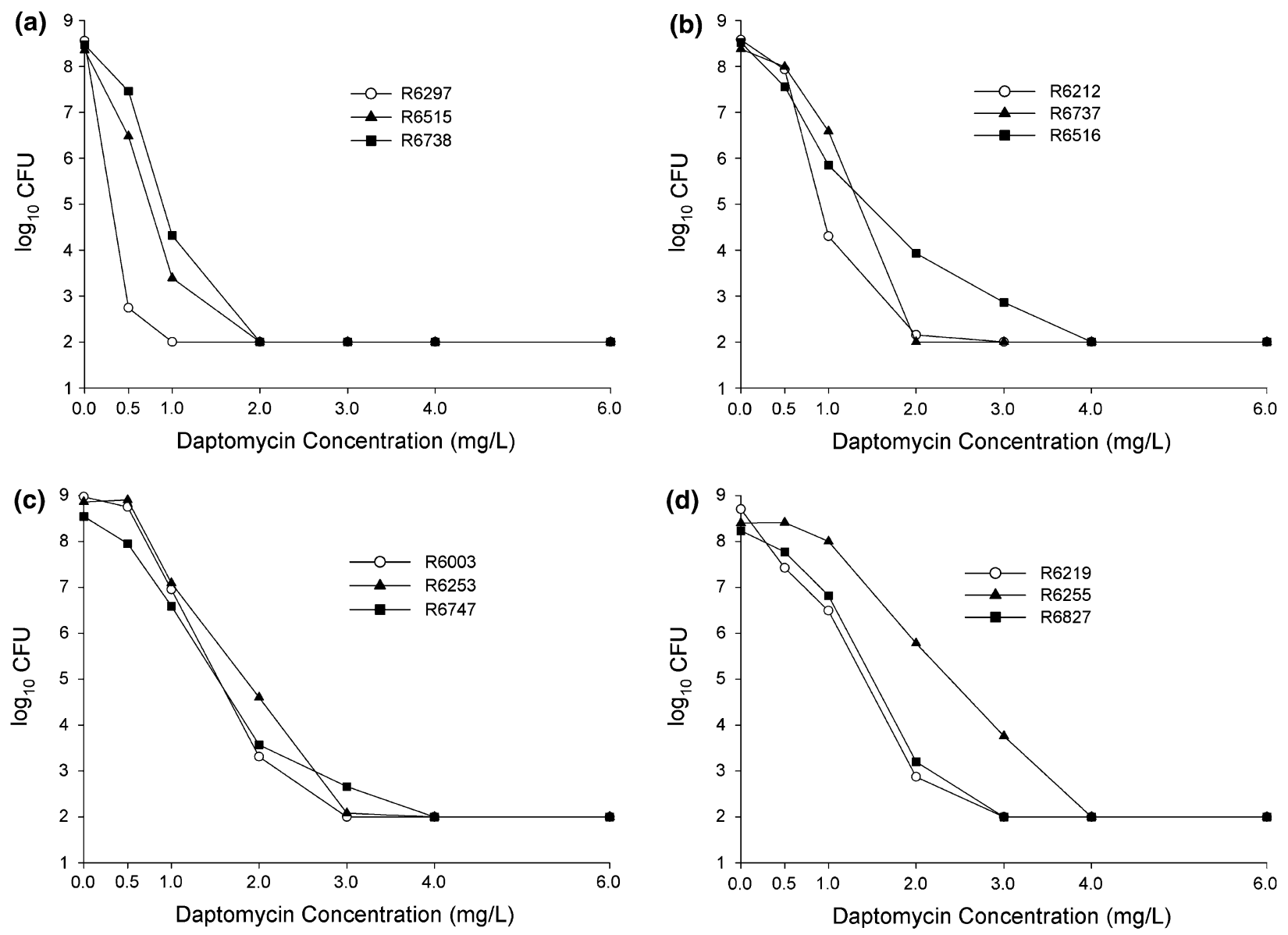

Fig. 1 Population analysis profiles for a Isolates with MIC values of $2 \mathrm{mg} / \mathrm{L}$ (Microscan) and $1 \mathrm{mg} / \mathrm{L}$ (Broth Microdilution, BMD). b Isolates with MIC values of

$2 \mathrm{mg} / \mathrm{L}$ (Microscan/BMD). c Isolates with MIC values of $4 \mathrm{mg} / \mathrm{L}$ (Microscan) and $2 \mathrm{mg} / \mathrm{L}$ (BMD). d Isolates with $\mathrm{MIC}$ values of $4 \mathrm{mg} / \mathrm{L}$ (Microscan/BMD)

initially had sustained bactericidal activity in the first $24 \mathrm{~h}$ against isolates with a left-shift population profile (R6003 and R6219) (Fig. 2a). In contrast, isolates with the same MIC value and a right-shift profile (R6253 and R6255) displayed bactericidal activity at $8 \mathrm{~h}$ but regrowth at $24 \mathrm{~h}$. The two left-shift isolates (R6003 and R6219) began to gradually regrow after $24 \mathrm{~h}$ eventually losing their bactericidal activity. In contrast, the two right-shift isolates displayed substantial killing and a more rapid regrowth with the $24 \mathrm{~h}$ dose before leveling off. The regimen of daptomycin $6 \mathrm{mg} / \mathrm{kg}$ maintained bactericidal activity against R6255

at $96 \mathrm{~h}$. No mutants were recovered. Observed pharmacokinetic parameters were 94.23-109 $\mathrm{mg} / \mathrm{L}$ and 6.78-7.42 h.

The isolates recovered at $96 \mathrm{~h}$ from the simulations of daptomycin $6 \mathrm{mg} / \mathrm{kg}$ did not have any change in MIC value from the initial isolates. However, examination of the population profiles revealed a rightward shift and increase in AUC. The AUC increased from 0 to $96 \mathrm{~h}$ for both R6003 (22.4 vs. 27.3) and R6219 (20.68 vs. 26.15). For isolates with an initial profile with a right shift, the AUC increase from 0 to $96 \mathrm{~h}$ for R6253 (23.66 vs. 27.31) and for R6253 (26.85 vs. 27.43) was less pronounced. 

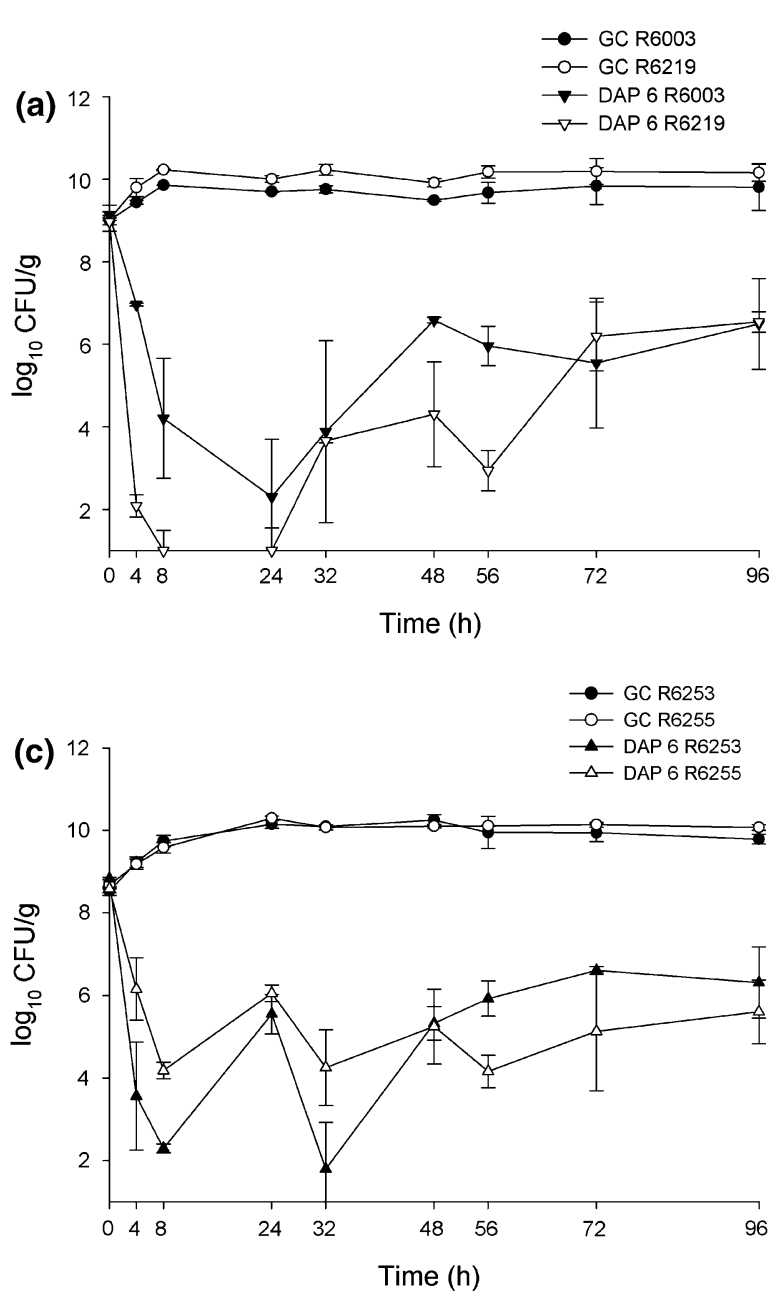

Fig. 2 a Activity of daptomycin $6 \mathrm{mg} / \mathrm{kg}$ against daptomycin left-shift strains R6003 \& R6219. b Activity of daptomycin $10 \mathrm{mg} / \mathrm{kg}$ against daptomycin left-shift strains R6003 and R6219. c Activity of daptomycin $6 \mathrm{mg} / \mathrm{kg}$ against daptomycin right-shift strains R6253 \&

All initial isolates evaluated in the in vitro PK/PD SEV model (R6003, R6219, R6253, and R6255), and derivatives recovered after $96 \mathrm{~h}$ of exposure to a simulated regimen of daptomycin $6 \mathrm{mg} / \mathrm{kg} /$ day, underwent sequence analyses of mprF. Both R6003 (P314L and E692Q) and R6253 (P314L) initially possessed mutations with no additional changes developing during further daptomycin exposure. Strain R6219 had a L826F mutation initially and acquired a Q326Stop mutation during exposure to the
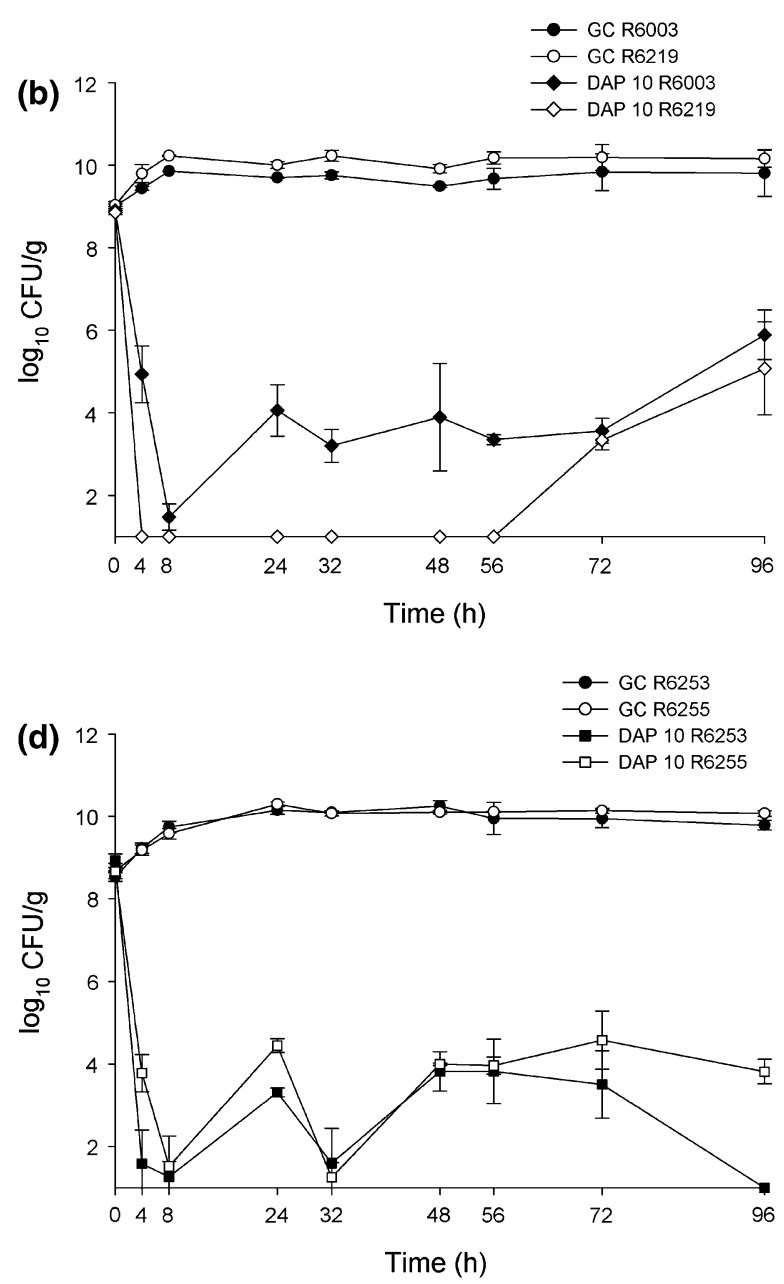

R6255. d Activity of daptomycin $10 \mathrm{mg} / \mathrm{kg}$ against daptomycin right-shift strains R6253 and R6255. DAP 6 Daptomycin $6 \mathrm{mg} / \mathrm{kg} / \mathrm{day}, D A P 10$ daptomycin $10 \mathrm{mg} / \mathrm{kg} /$ day, $G C$ growth control

simulated regimen of $6 \mathrm{mg} / \mathrm{kg} /$ day. Lastly, R6255 initially possessed an E692Q mutation and acquired the S337L mutation during daptomycin exposure.

The activity of daptomycin $10 \mathrm{mg} / \mathrm{kg}$ against the four tested isolates revealed a similar pattern as the daptomycin $6 \mathrm{mg} / \mathrm{kg}$ regimen. Daptomycin $10 \mathrm{mg} / \mathrm{kg}$ was bactericidal at 4 and $8 \mathrm{~h}$ against the two left-shift profile isolates (R6003 and R6219) with slow regrowth occurring for both strains by $96 \mathrm{~h}$ (Fig. 2b). In 

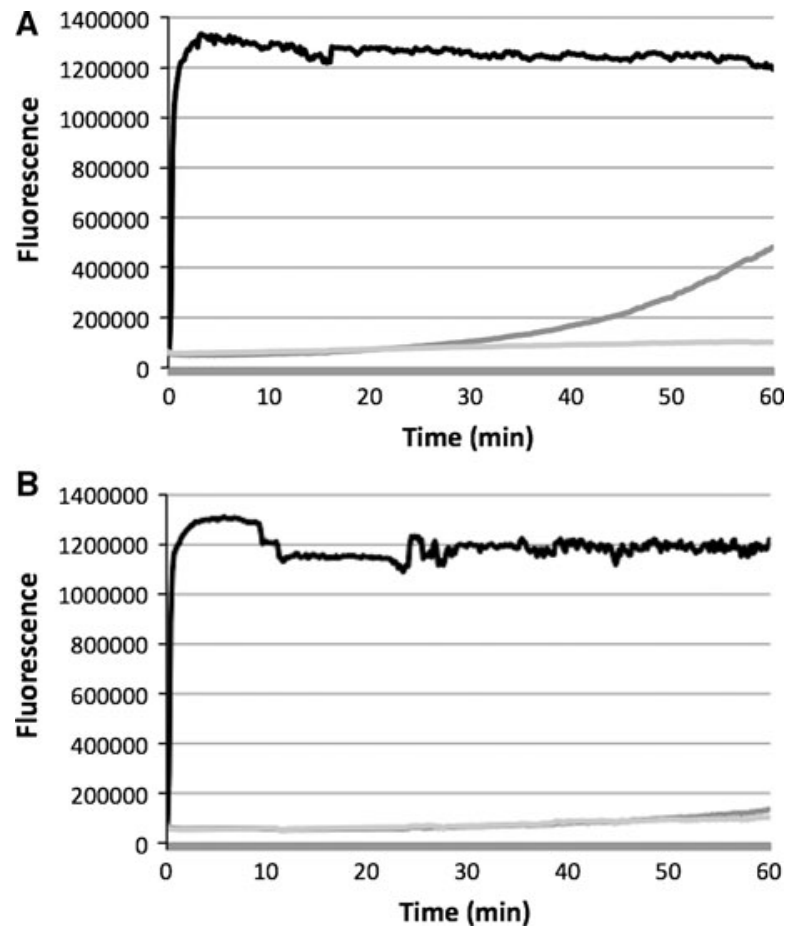

Fig. 3 Cytoplasmic membrane depolarization of the isogenic pair. a R6194 with daptomycin minimum inhibitory concentration of $0.25 \mathrm{mg} / \mathrm{L}$ and $\mathbf{b} \mathrm{R} 6212$ with daptomycin minimum inhibitory concentration value of $2 \mathrm{mg} / \mathrm{L}$. Black lines show results with nisin, dark grey lines show results with daptomycin, and light grey lines show results for control

contrast, against the right-shift isolates (R6253 and R6255) daptomycin $10 \mathrm{mg} / \mathrm{kg}$ resulted in multiple cycles of colony count decrease followed by regrowth. Bactericidal activity was maintained at $96 \mathrm{~h}$ for the two right-shift isolates. No mutants were recovered and isolates displayed no difference in MIC values at $96 \mathrm{~h}$. Observed pharmacokinetic parameters ranged 139.8-144.3 $\mathrm{mg} / \mathrm{L}$ and 6.9-8.3 h.

One daptomycin susceptible isogenic pair from the same patient (R6194, daptomycin MIC value $0.25 \mathrm{mg} / \mathrm{L}$, and R6212 daptomycin MIC value $2 \mathrm{mg} / \mathrm{L}$, clonality confirmed by PFGE) was available for depolarization testing. As can be seen in Fig. 3, the ability of daptomycin to depolarize the cytoplasmic membrane decreased from $35.57 \pm 2.12 \%$ for R6194 to $2.62 \pm 5.29 \%$ for R6212, $P=0.045$.

\section{DISCUSSION}

While the occurrence of DNS in $S$. aureus is relatively rare, there is still much room for discovery on mechanisms of resistance and optimal treatment. While multiple studies have examined both genetic and phenotypic changes found in both laboratory derived and clinical DNS $S$. aureus, limited work has examined the population profiles or stability of these strains. Additionally, to our knowledge no previous work has attempted to evaluate the relationship between daptomycin activity and the daptomycin PAPs of DNS S. aureus strains.

In the current study, we found all 12 of the clinical DNS $S$. aureus strains to be stable in nature as they did not revert to susceptible after serial passage on drug free agar. Previous work examining laboratory derived and clinical DNS $S$. aureus strains has revealed the occurrence of an unstable DNS $S$. aureus phenotype. A DNS $S$. aureus strain recovered previously from an in vitro PK/PD model reverted back to its susceptible state after serial passage on drug free agar [35]. Additionally, examination of the resistant subpopulations from a clinical isogenic daptomycin susceptible/DNS pair, SA-675 and SA-684, revealed that the resistant subpopulations were unstable [15]. Additionally, we found the majority (11/12) of strains to be stable in daptomycin MIC values after over 2 years of storage at $-80^{\circ} \mathrm{C}$. A recent paper examining daptomycin susceptible $S$. aureus strains found an overall decrease in MIC values after storage when tested by Etest [36]. This is in contrast to our study in which all but one strain was stable on repeat testing over two years later. These differences may be due to the 
testing method (Etest vs. BMD) or the MIC stability of daptomycin susceptible versus daptomycin non-susceptible $S$. aureus. While it appears from our work that the majority of all daptomycin non-susceptible clinical strains are indeed stable, further research in this area is needed to confirm these findings, as most studies to date have not examined the stability of DNS S. aureus clinical isolates.

In this study, we found variation in the susceptibility to daptomycin when the isolates were examined by population analysis with some isolates displaying prominent left or right shifts. Previous work has found the occurrence of daptomycin heteroresistance in both daptomycin susceptible and DNS $S$. aureus strains. Examination of the previously mentioned clinical isogenic pair, SA-675 and SA-684, by daptomycin population analysis revealed a heterogeneous profile [15]. Examination of a series of $S$. aureus isolates, ranging from daptomycin susceptible to DNS, recovered from a patient receiving high-dose daptomycin therapy by daptomycin population analysis revealed the presence of daptomycin heteroresistance on visual inspection both before and after the development of DNS [37]. In our study we also found a shift in the profile from the isolates recovered from the in vitro model after $96 \mathrm{~h}$ of exposure to daptomycin. This is consistent with the shift seen in clinical pairs analyzed after in vivo exposure to daptomycin [15, 37].

Examination of the impact of a DNS $S$. aureus daptomycin population profile on the activity of daptomycin in the in vitro PK/PD model of SEVs revealed unique killing patterns. The two isolates with left-shift profiles displayed one initial decrease in colony counts followed by a gradual regrowth, while the two right-shift profile isolates displayed multiple cycles of killing and regrowth. The extent of the antimicrobial activity may also be explained by the daptomycin PAPs. Compared to R6003, R6219 exhibited a greater decrease in colony counts when exposed to both daptomycin 6 and $10 \mathrm{mg} / \mathrm{kg}$ in the in vitro PK/PD SEV model despite having the same/higher daptomycin MIC value. These increases in susceptibility to daptomycin may be explained by the smaller AUC of the daptomycin PAP of R6219 (AUC 20.68) compared to R6003 (AUC 22.14). No correlation was observed, however, between the daptomycin PAP/AUC and the colony counts at $72-96 \mathrm{~h}$ in the in vitro PK/PD model.

Examination of our strains for mutations in the mprF gene revealed common mutations previously described including the E692Q, P314L, L826F and S337L. The finding of a premature stop codon, Q326Stop, in the R6219 $96 \mathrm{~h}$ isolate after daptomycin $6 \mathrm{mg} / \mathrm{kg}$ exposure is interesting as its position would be expected to interrupt the functional C-terminal domain of the mprF protein. Previous work has shown the mprF protein is comprised of two functional domains, the C-terminal and N-terminal. While the C-terminal could independently complete lysinylation of membrane phospholipids, the N-terminal was incapable of completing functions without the assistance of the C-terminal domain. The Q326Stop mutation would logically render the mprF protein non-functional.

While our study is novel in examining a large collection of DNS $S$. aureus strains for stability and PAP, it does have limitations. Firstly, due to the relative rarity of DNS $S$. aureus, our collection of examined isolates is small at 12 and we were only able to obtain a single daptomycin susceptible-DNS isogenic pair for comparison evaluation. We also used standard inocula $\left(\log 10^{6} \mathrm{CFU} / \mathrm{mL}\right)$ for broth microdilution and Etest susceptibility testing per CLSI and manufacturer's instructions, 
respectively. The results may have been different if we employed a high inoculum for susceptibility testing $\left(10^{9} \mathrm{CFU} / \mathrm{mL}\right)$ as was done for the PAP and in vitro PK/PD model of SEVs. Our study is also limited as it focused on the most common gene mutation in DNS $S$. aureus, mprf, and did not examine the isolates for mutations or changes in expression of other genes known to be involved in DNS $S$. aureus. Lastly, our isolates are from a single geographic area (Detroit, MI, USA) with an established history of cutting edge resistance in $S$. aureus and may not be representative of resistance patterns in other areas of the country.

\section{CONCLUSION}

All 12 DNS $S$. aureus isolates were stable and displayed different degrees of susceptibility when examined by PAP. To our knowledge, this is the first study to examine such a large collection of clinical DNS $S$. aureus strains and confirm their stability. This is also the first study to examine the impact of the daptomycin PAP on the activity of both standard and high dose simulated daptomycin. Additionally, an organism with a unique mutation in $m p r F$, Q326Stop, which would likely render the mprF protein non-functional, was discovered. The findings are clinically relevant because for some organisms the daptomycin AUC predicted antimicrobial activity or killing pattern better than the MIC value by BMD. This highlights the need to consider the whole population of bacteria when discussing susceptibility or the development of resistance. Despite previous reports that some aspects of DNS may be inducible and unstable, eleven of our twelve isolates displayed stable resistance even after 2 years of freezer storage confirming that DNS can frequently be a stable and not transient phenomenon in S. aureus. Daptomycin should continue to be utilized appropriately to minimize resistance and preserve its efficacy.

\section{ACKNOWLEDGMENTS}

This study was funded by an investigator initiated grant from Cubist pharmaceuticals. Michael J. Rybak is the guarantor for this article, and takes responsibility for the integrity of the work as a whole.

Conflict of interest. Michael J. Rybak has received grant support, has served as a consultant, or has participated as a speaker for Cubist, Durata, Forest, Theravance and Trius Pharmaceuticals. Hossein Salimnia has received grant support from BioFire Inc. Keith S. Kaye has received grant support, has served as a consultant, or has participated as a speaker for Cubist. Molly E. Steed, Ashley D. Hall, and Glenn W. Kaatz have no conflicts to declare.

Compliance with ethics guidelines. This article does not contain any studies with human or animal subjects performed by any of the authors.

Open Access. This article is distributed under the terms of the Creative Commons Attribution Noncommercial License which permits any noncommercial use, distribution, and reproduction in any medium, provided the original author(s) and the source are credited.

\section{REFERENCES}

1. Boucher HW, Sakoulas G. Perspectives on Daptomycin resistance, with emphasis on resistance in Staphylococcus aureus. Clin Infect Dis. 2007;45(5):601-8. 
2. Silverman JA, Perlmutter NG, Shapiro HM. Correlation of daptomycin bactericidal activity and membrane depolarization in Staphylococcus aureus. Antimicrob Agents Chemother. 2003;47(8):2538-44.

3. Safdar N, Andes D, Craig WA. In vivo pharmacodynamic activity of daptomycin. Antimicrob Agents Chemother. 2004;48(1):63-8.

4. Tedesco KL, Rybak MJ. Daptomycin. Pharmacotherapy. 2004;24(1):41-57.

5. Clinical and Laboratory Standards Institute. Methods for dilution antimicrobial susceptibility tests for bacteria that grow aerobically-ninth edition: approved standard M7-A9. Wayne: CLSI; 2011.

6. Silverman JA, Oliver N, Andrew T, Li T. Resistance studies with daptomycin. Antimicrob Agents Chemother. 2001;45(6):1799-802.

7. Rose WE, Rybak MJ, Tsuji BT, Kaatz GW, Sakoulas G. Correlation of vancomycin and daptomycin susceptibility in Staphylococcus aureus in reference to accessory gene regulator (agr) polymorphism and function. J Antimicrob Chemother. 2007;59(6):1190-3.

8. Fowler VG Jr, Boucher HW, Corey GR, Abrutyn E, Karchmer AW, Rupp ME, et al. Daptomycin versus standard therapy for bacteremia and endocarditis caused by Staphylococcus aureus. N Engl J Med. 2006;355(7):653-65.

9. Sader HS, Moet GJ, Farrell DJ, Jones RN. Antimicrobial susceptibility of daptomycin and comparator agents tested against methicillinresistant Staphylococcus aureus and vancomycinresistant enterococci: trend analysis of a 6-year period in US medical centers (2005-2010). Diagnostic microbiology and infectious disease. 2011;70(3):412-6 (Research Support, Non-U.S. Gov't).

10. Jones T, Yeaman MR, Sakoulas G, Yang SJ, Proctor RA, Sahl HG, et al. Failures in clinical treatment of Staphylococcus aureus Infection with daptomycin are associated with alterations in surface charge, membrane phospholipid asymmetry, and drug binding. Antimicrob Agents Chemother. 2008;52(1):269-78.

11. Friedman L, Alder JD, Silverman JA. Genetic changes that correlate with reduced susceptibility to daptomycin in Staphylococcus aureus. Antimicrob Agents Chemother. 2006;50(6):2137-45.

12. Yang SJ, Xiong YQ, Dunman PM, Schrenzel J, Francois P, Peschel A, et al. Regulation of mprF in daptomycin-nonsusceptible Staphylococcus aureus strains. Antimicrob Agents Chemother. 2009;53(6):2636-7.

13. Yang SJ, Kreiswirth BN, Sakoulas G, Yeaman MR, Xiong YQ, Sawa A, et al. Enhanced expression of dltABCD is associated with the development of daptomycin nonsusceptibility in a clinical endocarditis isolate of Staphylococcus aureus. J Infect Dis. 2009;200(12):1916-20.

14. Mishra NN, Yang SJ, Sawa A, Rubio A, Nast CC, Yeaman MR, et al. Analysis of cell membrane characteristics of in vitro-selected daptomycinresistant strains of methicillin-resistant Staphylococcus aureus. Antimicrob Agents Chemother. 2009;53(6):2312-8.

15. Kaatz GW, Lundstrom TS, Seo SM. Mechanisms of daptomycin resistance in Staphylococcus aureus. Int J Antimicrob Agents. 2006;28(4):280-7.

16. Ernst CM, Staubitz P, Mishra NN, Yang SJ, Hornig $\mathrm{G}$, Kalbacher $\mathrm{H}$, et al. The bacterial defensin resistance protein $\mathrm{MprF}$ consists of separable domains for lipid lysinylation and antimicrobial peptide repulsion. PLoS Pathog. 2009;5(11):e1000660.

17. Peleg AY, Miyakis S, Ward DV, Earl AM, Rubio A, Cameron DR, et al. Whole genome characterization of the mechanisms of daptomycin resistance in clinical and laboratory derived isolates of Staphylococcus aureus. PLoS One. 2012;7(1):e28316 (Research Support, N.I.H., Extramural Research Support, Non-U.S. Gov't).

18. Cui L, Isii T, Fukuda M, Ochiai T, Neoh HM, Camargo IL, et al. An RpoB mutation confers dual heteroresistance to daptomycin and vancomycin in Staphylococcus aureus. Antimicrob Agents Chemother. 2010;54(12):5222-33.

19. Mishra NN, Liu GY, Yeaman MR, Nast CC, Proctor RA, McKinnell J, et al. Carotenoid-related alteration of cell membrane fluidity impacts Staphylococcus aureus susceptibility to host defense peptides. Antimicrob Agents Chemother. 2011;55(2):526-31 (Research Support, N.I.H., Extramural).

20. Kilelee E, Pokorny A, Yeaman MR, Bayer AS. Lysylphosphatidylglycerol attenuates membrane perturbation rather than surface association of the cationic antimicrobial peptide $6 \mathrm{~W}-\mathrm{RP}-1$ in a model membrane system: implications for daptomycin resistance. Antimicrob Agents Chemother. 2010;54(10):4476-9.

21. Mishra NN, McKinnell J, Yeaman MR, Rubio A, Nast $\mathrm{CC}$, Chen $\mathrm{L}$, et al. In vitro cross-resistance to daptomycin and host defense cationic antimicrobial peptides in clinical methicillinresistant Staphylococcus aureus isolates. Antimicrob 
Agents Chemother. 2011;55(9):4012-8 (Research Support, N.I.H., Extramural Research Support, Non-U.S. Gov't).

22. Boyle-Vavra S, Jones M, Gourley BL, Holmes M, Ruf $\mathrm{R}$, Balsam AR, et al. Comparative genome sequencing of an isogenic pair of USA800 clinical methicillin-resistant Staphylococcus aureus isolates obtained before and after daptomycin treatment failure. Antimicrobial Agents Chemother. 2011;55(5):2018-25 (Case Reports Research Support, N.I.H., Extramural Research Support, Non-U.S. Gov't).

23. Yang SJ, Nast CC, Mishra NN, Yeaman MR, Fey PD, Bayer AS. Cell wall thickening is not a universal accompaniment of the daptomycin nonsusceptibility phenotype in Staphylococcus aureus: evidence for multiple resistance mechanisms. Antimicrob Agents Chemother. 2012;54(8):3079-85.

24. Pillai SK, Gold HS, Sakoulas G, Wennersten C, Moellering RC Jr, Eliopoulos GM. Daptomycin nonsusceptibility in Staphylococcus aureus with reduced vancomycin susceptibility is independent of alterations in MprF. Antimicrob Agents Chemother. 2007;51(6):2223-5.

25. Rose WE, Leonard SN, Rybak MJ. Evaluation of daptomycin pharmacodynamics and resistance at various dosage regimens against Staphylococcus aureus isolates with reduced susceptibilities to daptomycin in an in vitro pharmacodynamic model with simulated endocardial vegetations. Antimicrob Agents Chemother. 2008;52(9):3061-7.

26. Rose WE, Rybak MJ, Kaatz GW. Evaluation of daptomycin treatment of Staphylococcus aureus bacterial endocarditis: an in vitro and in vivo simulation using historical and current dosing strategies. J Antimicrob Chemother. 2007;60(2):334-40.

27. Lina G, Boutite F, Tristan A, Bes M, Etienne J, Vandenesch F. Bacterial competition for human nasal cavity colonization: role of Staphylococcal agr alleles. Appl Environ Microbiol. 2003;69(1):18-23.

28. Lina G, Piemont $Y$, Godail-Gamot F, Bes M, Peter MO, Gauduchon V, et al. Involvement of PantonValentine leukocidin-producing Staphylococcus aureus in primary skin infections and pneumonia. Clin Infect Dis Off Publ Infect Dis Soc Am. 1999;29(5):1128-32.

29. Strommenger B, Braulke C, Pasemann B, Schmidt C, Witte W. Multiplex PCR for rapid detection of Staphylococcus aureus isolates suspected to represent community-acquired strains. J Clin Microbiol. 2008;46(2):582-7 (Validation Studies).

30. Zhang K, McClure JA, Elsayed S, Louie T, Conly JM. Novel multiplex PCR assay for characterization and concomitant subtyping of staphylococcal cassette chromosome mec types I to $\mathrm{V}$ in methicillinresistant Staphylococcus aureus. J Clin Microbiol. 2005;43(10):5026-33 (Evaluation Studies Research Support, Non-U.S. Gov't).

31. Sakoulas G, Eliopoulos GM, Moellering RC Jr, Wennersten C, Venkataraman L, Novick RP, et al. Accessory gene regulator (agr) locus in geographically diverse Staphylococcus aureus isolates with reduced susceptibility to vancomycin. Antimicrob Agents Chemother. 2002;46(5):1492-502.

32. McDougal LK, Steward CD, Killgore GE, Chaitram JM, McAllister SK, Tenover FC. Pulsed-field gel electrophoresis typing of oxacillin-resistant Staphylococcus aureus isolates from the United States: establishing a national database. J Clin Microbiol. 2003;41(11):5113-20.

33. Tenover FC, Arbeit RD, Goering RV, Mickelsen PA, Murray BE, Persing $\mathrm{DH}$, et al. Interpreting chromosomal DNA restriction patterns produced by pulsed-field gel electrophoresis: criteria for bacterial strain typing. J Clin Microbiol. 1995;33(9):2233-9.

34. Benvenuto M, Benziger DP, Yankelev S, Vigliani G. Pharmacokinetics and tolerability of daptomycin at doses up to 12 milligrams per kilogram of body weight once daily in healthy volunteers. Antimicrob Agents Chemother. 2006;50(10):3245-9.

35. Rose WE, Leonard SN, Sakoulas G, Kaatz GW, Zervos MJ, Sheth A, et al. Daptomycin activity against Staphylococcus aureus following vancomycin exposure in an in vitro pharmacodynamic model with simulated endocardial vegetations. Antimicrob Agents Chemother. 2008;52(3):831-6.

36. Ludwig F, Edwards B, Lawes T, Gould IM. Effects of storage on vancomycin and daptomycin MIC in susceptible blood isolates of methicillin-resistant Staphylococcus aureus. J Clin Microbiol. 2012;50(10):3383-7.

37. Lee CH, Wang MC, Huang IW, Chen FJ, Lauderdale TL. Development of daptomycin nonsusceptibility with heterogeneous vancomycin-intermediate resistance and oxacillin susceptibility in methicillin-resistant Staphylococcus aureus during high-dose daptomycin treatment. Antimicrob Agents Chemother. 2010;54(9):4038-40. 